\title{
The Effects of
}

\section{Nuclear Weapons}

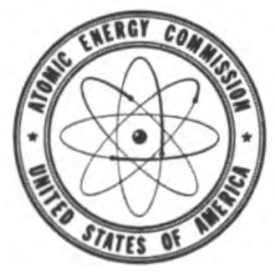

\section{Samuel Glasstone}

Editor

\section{Prepared by the}

UNITED STATES.DEPARTMENT OF DEFENSE

Published by the

UNITED STATES ATOMIC ENERGY COMMISSION

June 1957

For sale by the Superintendent of Documents, U. S. Government Printing Office Washington 25, D. C. - Price $\$ 2.00$ (paper bound) 